$\overline{\text { 報 文 }}$

\title{
食品中の甘味料分析における迅速な 改良透析法の開発
}

(平成 25 年 9 月 24 日受理)

$\begin{array}{ccc}\text { 田原正一 } *^{*} & \text { 藤原卓士 } & \text { 安井明子 } \\ \text { 早藤知惠子 } & \text { 小林千種 } & \text { 植松 洋子 }\end{array}$

A Rapid Dialysis Method for Analysis of Artificial Sweeteners in Food

Shoichi Tahara*, Takushi Fujiwara, Akiko Yasui, Chieko Hayafuj, Chigusa Kobayashi and Yoko Uematsu

Tokyo Metropolitan Institute of Public Health: 3-24-1 Hyakunin-cho, Shinjuku-ku, Tokyo 169-0073, Japan;

* Corresponding author

A simple and rapid dialysis method was developed for the extraction and purification of four artificial sweeteners, namely, sodium saccharin $(\mathrm{Sa})$, acesulfame potassium (AK), aspartame $(\mathrm{APM})$, and dulcin $(\mathrm{Du})$, which are present in various foods. Conventional dialysis uses a membrane dialysis tube approximately $15 \mathrm{~cm}$ in length and is carried out over many hours owing to the small membrane area and owing to inefficient mixing. In particular, processed cereal products such as cookies required treatment for 48 hours to obtain satisfactory recovery of the compounds. By increasing the tube length to $55 \mathrm{~cm}$ and introducing efficient mixing by inversion at half-hour intervals, the dialysis times of the four artificial sweeteners, spiked at $0.1 \mathrm{~g} / \mathrm{kg}$ in the cookie, were shortened to 4 hours. Recovery yields of $88.9-103.2 \%$ were obtained by using the improved method, whereas recovery yields were low $(65.5-82.0 \%)$ by the conventional method. Recovery yields (\%) of $\mathrm{Sa}, \mathrm{AK}, \mathrm{APM}$, and $\mathrm{Du}$, spiked at $0.1 \mathrm{~g} / \mathrm{kg}$ in various foods, were $91.6-100.1,93.9-100.1,86.7-$ 100.0 and 88.7-104.7 using the improved method.

(Received 24 September, 2013)

Key words: 食品food; サッカリンナトリウム sodium saccharin; アセスルファムカリウム acesulfame potassium; アスパルテーム aspartame; ズルチン dulcin; 透析法 dialysis method; 液体クロマトグ ラフィー HPLC

\section{緒言}

近年, 生活習慣病への危惧から糖質摂取を控える傾向が 強まり，甘味料を添加してカロリーを低減した食品は増加 している. そのため, 食品の検查機関において甘味料の検 查需要は高く, 検査の迅速化が常に求められている. 食品 中の甘味料分析操作では, 透析が共通の前処理として行わ れる。透析は特別な装置を必要とせず，操作が簡便で複数 の甘味料の系統的分析に適している ${ }^{11}$. しかし透析は終了 まで時間を要する．特に穀物調製品や魚介加工品等で 48 時間は必要とされ ${ }^{2), 3)}$, 試験検查迅速化の障害となってい る。そこでわれわれは，透析の利点を損なわず，短時間で 終了する改良透析法の開発を目的として検討を行った。そ

\footnotetext{
*連絡先 Shouichi_Tahara@member.metro.tokyo.jp 東京都健康安全研究センター： テ169-0073 東京都新宿区 百人町 $3-24-1$
}

の結果，従来 48 時間を要する試料の透析を，4時間で終了 可能な条件を見いだした.

\section{実験方法}

すべての操作は, 常時 $23 \sim 28^{\circ} \mathrm{C}$ の室温に保たれている 実験室で行った。
1. 試 料

東京都内で購入した，あらかじめサッカリンナトリウム $(\mathrm{Sa})$ ，アセスルファムカリウム $(\mathrm{AK})$ ，アスパルテーム $(\mathrm{APM})$ ，ズルチン $(\mathrm{Du})$ を含まないことを確認した食品 (クッキー, ビスケット，いちごジャム，ヨーグルト， ソース，麦茶，白菜漬，いずれも国産）を試料とした。

\section{2. 標準品・試薬}

標準品：Sa, AK, APMは和光純薬工業(株)製のそれぞ れ特級, 生化学用, 食品添加物試験用を, Duは関東化学 (株)製の食品分析用を用いた. 
添加用標準溶液 A：Du 200 mg を正確に量り, 少量のメ タノールに溶解した。次に $\mathrm{Sa}, \mathrm{AK}$ 各 $200 \mathrm{mg}$ を正確に量 り，Du溶液とともに水を加えて正確に $100 \mathrm{~mL}$ とし，添 加用標準溶液 $\mathrm{A}$ とた（本液 $1 \mathrm{~mL}$ は $\mathrm{Sa}, \mathrm{AK}, \mathrm{Du}$ を各 2 $\mathrm{mg}$ 含む).

添加用標準溶液 B：APM $200 \mathrm{mg}$ を正確に量り, 0.01 $\mathrm{mol} / \mathrm{L}$ 塩酸を加えて正確に $100 \mathrm{~mL}$ と, 添加用標準溶液 $\mathrm{B}$ とした（本液 $1 \mathrm{~mL}$ は $\mathrm{APM}$ を $2 \mathrm{mg}$ 含む).

添加用標準溶液 C：Sa $200 \mathrm{mg}$ を正確に量り, 水を加え て正確に $100 \mathrm{~mL}$ とし, 添加用標準溶液 Cとした（本液 1 $\mathrm{mL}$ は $\mathrm{Sa} 2 \mathrm{mg}$ 含む)

透析内液 (内液)：塩化ナトリウム $100 \mathrm{~g}$ を $1 \mathrm{~mol} / \mathrm{L}$ 塩酸 $10 \mathrm{~mL}$ および水に溶解して，全量を $1,000 \mathrm{~mL}$ とした.

透析外液 (外液) : $0.01 \mathrm{~mol} / \mathrm{L}$ 塩酸.

回収率算出用基準溶液：添加用標準溶液 $\mathrm{A}, \mathrm{B}$ 各 $1 \mathrm{~mL}$ を 透析用メスシリンダー (透析管) に入れ, 透析外液で全体

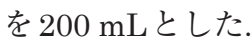

その他の試薬：メタノールおよびアセトニトリルは HPLC用，その他の試薬は市販特級品を用いた.

メンブレンフィルターはMLLIPORE社製MILLEX LH （親水性PTFE, 直径 $13 \mathrm{~mm}$, 孔径 $0.45 \mu \mathrm{m}$ ）を用いた.

\section{3. 器具および装置}

透析チューブ：透析用セルロースチューブ 36/32（透過 分子量 14,000 , 孔径 $50 \AA$, 平面幅 $44 \mathrm{~mm}$, 直径 $28 \mathrm{~mm}$, 壁厚 $0.0203 \mathrm{~mm}$, Viskase 社製).

透析管： $200 \mathrm{~mL}$ まで $50 \mathrm{~mL}$ 刻みに目盛りを付けた平底 試験管（高さ $23.3 \mathrm{~cm}$, 内径 $44.6 \mathrm{~mm}$, 肉厚 $2 \mathrm{~mm}$, 前田 製作所 (株) 製)

紐：約 $30 \mathrm{~cm}$ の長さに切り, 4つに裂いたポリエチレン 製玉巻きテープ（幅 $5 \mathrm{~cm}, 400 \mathrm{~g} / 400 \mathrm{~m}$, 新潟エースロー プ(株) 製).

蓋：サンプル瓶用中栓（内径 $40 \mathrm{~mm}$, 三商(株)製)，およ びパラフィルム（PM-996, Bemis Company, Inc., Neenah, WI, USA).

フードプロセッサー：HFP-B3（日立リビングサプライ (株) 製)

恒温水槽：BW101（ヤマト科学(株)製).

HPLC システム (PDA検出器付)：ウォーターズ 2695 セパレーションモジュール，日本ウォーターズ(株)製.

\section{HPLC 条件}

SaおよびAK用カラム：Cosmosil 5NH2-MS (4.6 mm i.d. $\times 250 \mathrm{~mm}$, 粒径 $5 \mu \mathrm{m}$ ), ナカライテスク (株) 製, 移動 相: メ夕ノール・1\%リン酸 $(6: 4)$, 流速： $1 \mathrm{~mL} / \mathrm{min}$, 検出：UV $230 \mathrm{~nm}$, カラム温度： $40^{\circ} \mathrm{C}$, 注入量： $10 \mu \mathrm{L}$.

$\mathrm{APM}$ おび゙ Du用カラム: Mightysil RP18-GP (4.6 $\mathrm{mm}$ i.d. $\times 250 \mathrm{~mm}$, 粒径 $5 \mu \mathrm{m}$ ), 関東化学(株) 製, 移動 相：メタノール・20 mmol/Lリン酸二水素ナトリウム (1:3), 流速： $1 \mathrm{~mL} / \mathrm{min}$, 検出波長：UV $210 \mathrm{~nm}$, カラ 么温度： $40^{\circ} \mathrm{C}$, 注入量： $10 \mu \mathrm{L}$

\section{5. 甘味料の添加方法}

液体試料はそのまま，固形試料についてはフードプロ セッサーで断続的に合計 1 分程度細切し，添加用標準溶液 $\mathrm{A}$ を甘味料の濃度が $0.1 \mathrm{~g} / \mathrm{kg}$ となるよう添加して混合後, 48 時間以上室温下で放置した。次いで添加用標準溶液 B を, 甘味料の濃度が $0.1 \mathrm{~g} / \mathrm{kg}$ となるよう添加して混合後, 1〜2時間室温下で放置した。

\section{6. 試験溶液の調製}

試料（20 g) を，内液 $(20 \mathrm{~mL})$ とともに一方を結び閉 じた長さ $65 \mathrm{~cm}$ の透析チューブに充填した．空気を残さな いようもう一方を結び閉じ，両端の結びしろを除去して， 透析チューブの長さ (有効長) を $55 \mathrm{~cm}$ とした。内容物を

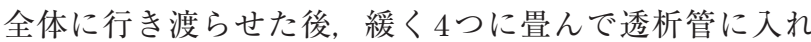
た．外液を加えて全量を $200 \mathrm{~mL}$ とした後，蓋とパラフィ ルムで密栓し，室温下で透析を開始した．混和は，30分 ごとに 10 回上下反転して行い，次回の混和まで反転放置 した。透析は 4 時間で終了し，外液を $0.45 \mu \mathrm{m}$ のフィル ターでろ過して, HPLC用試験溶液とした。

\section{7. 回収率の算出方法および統計処理}

回収率を求める検討は, 試行回数 5 回で行い, 同時に調 製した回収率算出用基準溶液中の甘味料濃度を $100 \%$ とし て, 平均值（相対標準偏差）で表した，後述する有効長の 違いが定量值に及ぼす影響の検討は，試行回数 9 回で行 い, 平均值（相対標準偏差）で表し，各群の統計的な比較 を, Stat View 4.5 (Abacus Concepts, Inc., CA, USA) の Student $t$-testにより行った。 $p$ 值が 0.05 以下の場合, 有 意差があるとした。

\section{結果および考察}

\section{1 改良透析法の概念}

透析法は，溶液中の物質の拡散による移動を利用した， 半透膜内外の溶液濃度の差を駆動力とする分離精製法であ $ろ^{4)}$. 一般的に，透析の迅速化には，物質の移動を促進さ せる加温 ${ }^{5)}$, 6) や，透析が進行するに伴い小さくなる半透膜 近傍の濃度差を回復させ，駆動力の低下を抑制する溶液の 混和 $\left.{ }^{5)}, 7\right)$ ，および物質が半透膜を透過する場を増やすため の, 内容液量に対する半透膜表面積比の増加や, 物質の半 透膜までの移動距離を短縮することが効果的である ${ }^{5), 8), 9) . ~}$ しかし, 食品中の食品添加物分析における, 半透膜に透析 チューブを用いる透析の迅速化に関して，これまで加 温 ${ }^{10) \sim 12)}$ や混和方法 ${ }^{13) \sim 16)}$ (検討されているが，膜表面積 や移動距離は検討されておらず，有効長が明記された例も ほとんどない ${ }^{17)}$ ，そこで，われわれは甘味料を用い検討 を行った。すなわち，有効長を長くして膜表面積を増や し，透析時間の短縮を図った。

\section{2 検討方法の概要}

既存の透析法 ${ }^{2}$, 3), 18), 19) の有効長や混和方法, 混和頻度 は曖昧であり，再現性にそしいことが示唆された。そこで 諸条件を定め，対照としての従来法とした，次いで，有効 長を従来法で用いる長さにそろえて添加回収試験を行い, 
Table 1. Effect of mixing method on recoveries of sweeteners spiked in cookie

\begin{tabular}{llccccc}
\hline \hline \multirow{2}{*}{ Sweetener } & \multirow{2}{*}{$\begin{array}{l}\text { Mixing } \\
\text { method }\end{array}$} & \multicolumn{5}{c}{ Dialyzing time $(\mathrm{hr})$} \\
\cline { 3 - 7 } & & 2 & 4 & 6 & 24 & 48 \\
\hline \multirow{2}{*}{ Saccharin Na } & Vertical & $20.3(6.5)$ & $29.4(6.6)$ & $35.7(7.7)$ & $57.0(5.8)$ & $72.5(2.8)$ \\
& Inversion & $23.9(12.1)$ & $43.7(9.8)$ & $56.2(9.5)$ & $78.9(7.5)$ & $87.7(3.4)$ \\
\hline \multirow{2}{*}{ Acesulfame K } & Vertical & $23.1(6.4)$ & $33.4(6.4)$ & $41.0(8.0)$ & $65.3(4.7)$ & $82.0(2.0)$ \\
& Inversion & $27.1(11.7)$ & $48.8(9.9)$ & $62.4(10.0)$ & $86.3(6.9)$ & $94.8(2.4)$ \\
\hline \multirow{2}{*}{ Aspartame } & Vertical & $19.9(12.5)$ & $29.5(9.0)$ & $36.9(8.9)$ & $63.3(7.1)$ & $80.5(3.7)$ \\
& Inversion & $23.3(15.7)$ & $44.2(11.8)$ & $59.1(10.9)$ & $88.3(7.5)$ & $99.3(3.5)$ \\
\hline \multirow{2}{*}{ Dulcin } & Vertical & $17.9(9.5)$ & $25.4(8.2)$ & $31.5(7.8)$ & $51.1(7.9)$ & $65.5(4.9)$ \\
& Inversion & $20.5(15.7)$ & $39.3(11.0)$ & $51.5(9.8)$ & $74.8(8.2)$ & $84.6(5.4)$ \\
\hline
\end{tabular}

Each sweetener was spiked at $0.1 \mathrm{~g} / \mathrm{kg}$. The membrane tube was $15 \mathrm{~cm}$ long. "Vertical" indicates the dialysis membrane tube was swung 10 times vertically at 2, 4, 6, 24 and 48 hours. "Inversion" indicates the dialysis container was inverted 10 times at 2, 4, 6, 24 and 48 hours. Each value represents the mean (RSD) (\%) of five solutions.

混和方法を検討した，検討用の試料には，Saの回収率が 穀物調製品で低いことや ${ }^{2)}$, 入手の容易さ等を考虑して クッキーを用いた。また，APMが酸性条件下で安定なた め ${ }^{20)}$ ，添加用標準溶液Bは外液で調製した。さらに，甘 味料の添加量を一定にし, 透析液量と透析チューブの総量 を一定にした場合, 有効長の違いが透析液中の甘味料濃度 に影響するか調べた，次いで混和方法をそろえ，有効長の 違いによる回収率の比較を行った，さらに，混和頻度，透 析温度についても検討して改良透析法を定めた。最後に, 改良透析法が種々の食品に適用可能か検討した。

\section{2. 透析方法の検討}

\section{1 従来法に必要な諸条件の設定}

透析管の高さに規定される有効長は, 紐を用いて透析管 に吊るした際に，透析チューブ全体が外液に浸る最大長 （15cm）とし，膜面積比が大きくなるよう考慮した．混 和は, 吊るした紐を持ち, 上下する方法 $(\text { 上下混和法 })^{13)}$ を, 落差 $10 \mathrm{~cm}$ で 10 往復行った. 混和頻度は, 開始後 6 時間まで 2 時間ごととし，以降は 24 時間ごととした．

\section{2 混和法の検討}

透析管内に紐で吊るせないほど有効長を長くした場合, 上下混和が困難であった。 そこで，透析管を密栓して 10 回転倒して混和し, 次回の混和まで上下逆さまに放置する 方法（転倒混和法）を行い，上下混和法と比較した．有効 長と混和頻度は従来法に準じた。

その結果，すべての甘味料の回収率は，Table 1 に示す ように，同じ透析時間の従来法よりも常に高く，24時間 で従来法の 48 時間後の值を上回り，いずれも $70 \%$ を超え た.48時間後の回収率（\%）はさらに増加し, Sa, AK, APM, Duがそれぞれ 87.7, 94.8, 99.3, 84.6に達した。 上 下混和法は, 混和を行った直後でも透析チューブ下部に クッキー残さが沈殿したままで, 内液の混和が不十分なこ とが示唆された。一方, 転倒混和法は, 内液の混和が容易 で，混和ごとに沈殿物が内液中に分散することや，次回の
Table 2. Effect of dialysis membrane tube length on concentration of saccharin $\mathrm{Na}$ in external dialysis solution

\begin{tabular}{ccc}
\hline \hline $\begin{array}{c}\text { Dialysis membrane } \\
\text { length }(\mathrm{cm})\end{array}$ & $\begin{array}{c}\text { Concentration } \\
\text { ratio }(\%)\end{array}$ & $p$ Value \\
\hline 0 (Control) & $100.0(0.1)$ & \\
15 & $100.4(0.5)$ & 0.12 \\
55 & $100.1(0.1)$ & 0.46 \\
100 & $100.3(0.5)$ & 0.17 \\
200 & $101.1(0.4)^{*}$ & $<0.0001$ \\
\hline
\end{tabular}

Saccharin $\mathrm{Na}$ was spiked at $2 \mathrm{mg}$ in each dialysis solution. Each value represents the mean (RSD) of nine solutions. The asterisk indicates significant differences between the control and the indicated dialysis membrane tube length. The $p$ values less than 0.05 were considered as representing significant differences.

混和まで逆さまに放置し，沈殿形成を抑制したことが，良 好な回収率の原因であることが示唆された，以降の検討で は，転倒混和法を用いた。

\section{3 透析チューブ長の検討 \\ 2.3.1 有効長の違いが定量值に及ぼす影響}

有効長を長くすると，透析チューブの体積は増加する. 透析の全体積が一定の場合，有効長を長くすると，定容に 使用する外液量は，有効長が短い条件と比較して減少す る。透析チューブの材質に，甘味料が外液と同濃度存在す る場合，透析チューブの使用量によって外液中の甘味料濃 度は変化しないが, 同濃度存在しない場合, 外液中の甘味 料濃度が相対的に高くなる懸念が生じた，そこで，使用す る透析チューブの長さの違いが，甘味料の定量值に影響す るか検討した．有効長（cm）が15, 55, 100，および200の 透析チューブを細断して透析管に入れた．次いで添加用標 準溶液 C $(1.0 \mathrm{~mL})$ ，および外液を加えて全体を $200 \mathrm{~mL}$ と し，全体を混合して試験溶液を得た。添加用標準溶液 $\mathrm{C}$ （1.0 mL）を透析管に入れ，外液で $200 \mathrm{~mL}$ とした溶液も 
Table 3. Effect of mixing interval time on recoveries of sweeteners spiked in cookie

\begin{tabular}{|c|c|c|c|c|c|c|}
\hline \multirow{2}{*}{ Sweetener } & \multirow{2}{*}{$\begin{array}{c}\text { Mixing interval } \\
(\mathrm{hr})\end{array}$} & \multicolumn{5}{|c|}{ Dialyzing time $(\mathrm{hr})$} \\
\hline & & 2 & 4 & 6 & 24 & 48 \\
\hline \multirow{2}{*}{ Saccharin $\mathrm{Na}$} & 2 & $59.9(4.7)$ & $84.4(1.6)$ & $89.4(0.8)$ & $91.4(0.8)$ & $91.8(0.3)$ \\
\hline & 0.5 & $82.7(1.0)$ & $93.3(1.3)$ & $92.9(0.8)$ & $91.9(0.8)$ & No Data. \\
\hline \multirow{2}{*}{ Acesulfame $\mathrm{K}$} & 2 & $66.3(4.0)$ & $91.9(1.6)$ & $96.2(0.9)$ & $97.6(1.3)$ & $98.2(1.4)$ \\
\hline & 0.5 & $90.7(1.1)$ & $98.3(0.6)$ & $98.6(0.5)$ & $98.3(0.4)$ & No Data. \\
\hline \multirow{2}{*}{ Aspartame } & 2 & $65.6(5.4)$ & $93.5(2.5)$ & $102.1(1.1)$ & $105.8(1.4)$ & $105.3(0.7)$ \\
\hline & 0.5 & $88.4(1.3)$ & $103.2(1.0)$ & $104.1(1.1)$ & $104.2(1.0)$ & No Data. \\
\hline \multirow{2}{*}{ Dulcin } & 2 & $53.7(5.2)$ & $80.0(2.6)$ & $86.5(1.4)$ & $90.3(0.9)$ & $91.0(0.6)$ \\
\hline & 0.5 & $77.6(1.5)$ & $88.9(1.0)$ & $89.5(0.7)$ & $89.8(1.6)$ & No Data. \\
\hline
\end{tabular}

Each sweetener was spiked at $0.1 \mathrm{~g} / \mathrm{kg}$. "Mixing interval" indicates intervals up to 6 hours. In addition, each solution was mixed at 24 and 48 hours. Each dialysis used the membrane tube length of $55 \mathrm{~cm}$ and the dialysis container was inverted at the indicated intervals under room temperature. Each value represents the mean (RSD) (\%) of five solutions.

Table 4. Recoveries of sweeteners spiked in cookie at $50^{\circ} \mathrm{C}$

\begin{tabular}{lcrrr}
\hline \hline \multirow{2}{*}{ Sweetener } & \multicolumn{5}{c}{ Dialyzing time $(\mathrm{hr})$} \\
\cline { 2 - 5 } & 1 & \multicolumn{1}{c}{2} & \multicolumn{1}{c}{3} \\
\hline Saccharin Na & $74.9(4.4)$ & $92.7(2.0)$ & $96.1(0.4)$ & $96.0(0.7)$ \\
Acesulfame K & $81.8(4.1)$ & $98.6(1.5)$ & $102.1(0.7)$ & $101.7(0.5)$ \\
Aspartame & $57.5(1.7)$ & $82.0(1.8)$ & $93.0(0.8)$ & $99.0(1.0)$ \\
Dulcin & $54.1(5.6)$ & $78.1(4.5)$ & $89.3(2.8)$ & $94.8(2.0)$ \\
\hline
\end{tabular}

Each sweetener was spiked at $0.1 \mathrm{~g} / \mathrm{kg}$. The membrane tube was $55 \mathrm{~cm}$ long. The dialysis container was inverted at the indicated intervals up to 4 hours. Each value represents the mean (RSD) (\%) of five solutions.

Table 5. Recoveries of sweeteners spiked in various foods

\begin{tabular}{lccrr}
\hline \hline \multirow{2}{*}{ Food } & \multicolumn{4}{c}{ Recovery $(\%)$} \\
\cline { 2 - 5 } & Saccharin Na & Acesulfame K & Aspartame & Dulcin \\
\hline Biscuit & $93.1(0.2)$ & $99.1(0.2)$ & $99.8(0.4)$ & $88.7(0.9)$ \\
Strawberry jam & $99.4(0.4)$ & $99.5(0.6)$ & $100.0(0.8)$ & $97.8(0.9)$ \\
Yogurt & $91.6(1.1)$ & $93.9(1.5)$ & $98.4(1.7)$ & $99.0(1.0)$ \\
Sauce & $99.3(0.4)$ & $100.1(0.4)$ & $96.0(1.2)$ & $98.1(0.9)$ \\
Barley tea & $100.1(0.5)$ & $99.8(0.4)$ & $98.9(0.6)$ & $99.9(0.6)$ \\
Chinese cabbage pickles & $99.3(2.1)$ & $99.2(1.9)$ & $86.7(3.3)$ & $104.7(2.1)$ \\
\hline
\end{tabular}

Each sweetener was spiked at $0.1 \mathrm{~g} / \mathrm{kg}$. Each dialysis used the membrane tube length of $55 \mathrm{~cm}$. The dialysis container was inverted every 0.5 hours up to 4 hours under room temperature. Each value represents the mean (RSD) (\%) of five solutions.

調製した.

その結果, Table 2 に示すように, 有効長 $100 \mathrm{~cm}$ までの $\mathrm{Sa}$ 濃度は，透析チューブを入れずに調製した溶液との間 に有意差が認められなかった。しかし，クッキーを試料と して用いた透析操作において, $20 \mathrm{~mL}$ の内液量では, 有効 長が $55 \mathrm{~cm}$ を超えた場合, 試料を均一に充填することが困 難だったので, 以降の検討は, 有効長 $55 \mathrm{~cm}$ で行った.

\subsection{2 有効長を延長した場合の透析時間短縮効果}

有効長 $55 \mathrm{~cm}$ の透析チューブを用い, 開始後 6 時間まで 2 時間ごと, および 24 時間後, 48 時間後に転倒混和する 透析を 2.2 と同様に行い, 結果をTable 3 , 混和間隔 2 時間
の部分に示した.

検討した甘味料のすべてで, 回収率は従来法に比べ開始 2 時間後でも高く, 透析開始 6 時間後に, Table 1 で示した 有効長 $15 \mathrm{~cm}$, 転倒混和法の 48 時間後の值を超え, Sa, $\mathrm{AK}, \mathrm{APM}, \mathrm{Du}$ の回収率 $(\%)$ が，それぞれ89.4, 96.2, 102.1，86.5に達した。試料および内液量を一定にして有 効長を延長すると，透析チューブは表面積が増加すると同 時に平たくなり, 膜面までの移動距離が短縮することも, 透析の著しい迅速化に寄与することが示唆された.

\section{4 混和頻度の増加による透析時間短縮効果}

透析の更なる迅速化を図るため, 開始 6 時間後までの混 
和頻度を 30 分ごとに増やし, 開始 24 時間後に終了する透 析を，2.3.2 と同様に行った。 その結果, Table 3 に示すよ うに, 回収率 (\%) は混和頻度 2 時間ごとよりも良好で, 開始 4 時間後の Sa, AK, APM, Duが，それぞれ 93.3, 98.3, 103.2, 88.9に達した. 回収率は 4 時間以降, それほど変化 せず，透析が 4 時間で終了したことが示唆された。以降の 検討では，混和頻度を 30 分ごと，透析時間を最長 4 時間 とした。

\section{5 加温による透析時間短縮効果}

加温による透析の迅速効果を検討した. APMは熱に不 安定だが, 酸性条件下, $50^{\circ} \mathrm{C}$ で安定なので ${ }^{20)}$, 温度 $50^{\circ} \mathrm{C}$ の恒温水槽を用いて加温しつつ透析を行った。透析管が $150 \mathrm{~mL}$ の深さで浸るよう水深を調整した.

その結果, Table 4に示すように, Sa, AK, APM, Duに おける開始 3 時間後の回収率（\%）は，それぞれ 96.1 , 102.1, 93.0, 89.3 と, 2.4の 4 時間後と同等の高い值を得 た。しかし，加温による透析時間短縮効果は弱く，一度に 処理可能な試料数が, 水槽の容積に依存する点で, 日常の 透析操作として不適当なことが示唆された. 以上の結果か ら，“実験方法 6. 試験溶液の調製” に示した方法を，本 研究における改良透析法とした.

\section{3. 種々の食品の改良透析法による添加回収試験}

本改良透析法が種々の食品に適用可能か, ビスケット, いちごジャム, ヨーグルト, ソース, 麦茶, 白菜漬を試料 として添加回収試験を行った。

その結果, Table 5 に示すように $\mathrm{Sa}, \mathrm{AK}, \mathrm{APM}, \mathrm{Du}$ の回 収率（\%）は，91.6〜100.1, 93.9〜100.1, 86.7〜100.0, 88.7 〜 104.7 と, いずれの食品でもクッキーと同様の高い值を 得た。以上の結果から, 改良透析法が種々の食品に適用可 能なことが示唆された.

\section{結語}

食品中の甘味料分析では，透析時間の長さが総分析時間 に与える影響が大きい。透析時間の短縮には，これまで検 討されていなかった透析チューブ長の延長が有効であるこ とが, 本研究により示唆された. 改良透析法は, 従来の透 析条件に，透析チューブ長と混和方法を追加しただけの簡 便な方法であるが, 従来 48 時間要した透析時間を，4時間 まで著しく短縮した，改良透析法の改善点は，透析に関す る普遍的な迅速法であり, 他の甘味料や保存料など, 透析 を用いる食品添加物分析全般に広く適用可能と考えられ た．普段使用している器具，試薬などをそのまま用いる本 改良透析法により, 甘味料試験検査の大幅な迅速化が可能 となった。

\section{文献}

1) Matsumoto, H., Hirata, K., Sakamaki, N., Hagino, K., Ushiyama, H. Determination of cyclamate and dulcin by HPLC and LC/MS/MS and systematic analysis of eight types of sweeteners. Kagaku Seibutu Sougou Kan- ri, 6, 25-35 (2010).

2) Moriyasu, T., Nakazato, M., Kobayashi, C., Kikuchi, Y., Hayano, K., Tamura, Y. Determination of acesulfame $\mathrm{K}$, saccharin and aspartame in various foods by HPLC. Shokuhin Eiseigaku Zasshi (Food Hyg. Sef. Sci.), 37, 91-96 (1996).

3）厚生労働省監修。“第 10 章 甘味料”。食品衛生検査指針 食品添加物編. 東京, 日本食品衛生協会, 2003, p. 215241.

4）飯田 隆, 菅原正雄, 鈴鹿 敢, 辻 智也, 宮入伸一編. “11透析”。イラストで見る化学実験の基礎知識第 3 版。東 京, 丸善, 2009, 258 p. (ISBN 978-4-621-08088-7)

5）化学実験操作法便覧編集委員会編. “透析，電気透析”化 学実験操作法便覧. 東京, 誠文堂新光社, 1960, p. 160166.

6) Davit, T. Plummer (Hiromi, K. et al. trsl.) An Introduction to Practical Biochemistry, 2nd ed. (Jikken De Manabu Seikagaku) Tokyo, Kagaku Doujin, 1981, p. 45-49. (ISBN 978-4-759-80084-5)

7）荻原文二，橋本光一．“5.5.2透析の促進法”。膜による分 離法. 東京, 講談社, 1974, p. 208-209.

8）日本化学会編. “4.9 透析”. 新実験化学講座 1 基本操作 [I]. 東京, 丸善, 1975 , p. 498-500.

9）岡田雅人，宮崎 香編。“ $2-5$ 透析”。タンパク質実験ノー 卜〈上〉抽出と分離精製．東京，羊土社， 1996，p. 78-80. (ISBN 4-89706-911-4)

10) Inoue, T., Kawamura, T., Kamijo, M., Asakura, M. Studies on the preservatives in foods (II). Separation of sorbic acid by dialysis. Eisei Kagaku, 10, 47-51 (1964).

11) Inoue, T., Hayashi, T, Nakamura, S., Kawamura, T., Asakura, M. Studies on determination of dulcin in foods (2). Method of determination of dulcin in foods. Shokuhin Eiseigaku Zasshi (Food Hyg. Saf. Sci.), 9, 312-316 (1968).

12) Sakamaki, N., Matsumoto, H., Hagino, K., Nakazato, M., Yasuda, K. Simultaneous determination of stevioside, rebaudioside A and glycyrrhizic acid in foods by HPLC. Shokuhin Eiseigaku Zasshi (Food Hyg. Saf. Sci.), 45, 81-86 (2004).

13) Miyakoda, M., Aoyagi, Y., Satoh, H., Takada, C., Yamada, Y., Ogiwara, T., Amakawa, E., Yasuda, K. Determination of saccharin and dulcin in jam and marmalade by HPLC. Tokyo Kenko Anzen Kenkyu Senta Kenkyu Nenpo (Annual Report of Tokyo Metropolitan Institute of Public Health), 52, 57-61 (2001).

14) Inoue, S., Miyamoto, S., Ogasawara, S., Oseto, M., Inoue, $\mathrm{H}$. A study on determination of sodium saccharin in foods by HPLC with zirconia carbon column. Ehimeken Eiseikankyo Kenkyujyo Nenpo, 7, 33-37 (2004).

15) Takai, Y., Kuno, K., Sando, H. Rapid and simultaneous determination of sweeteners. Wakayamaken Kankyo Eisei Kenkyu Senta Nenpo (Annual Report of Wakayama Prefectural Research Center of Environment and Public Health), 54, 35-37 (2008).

16) Takai, Y., Kuno, K., Sando, H. Development of rapid dialysis method for food analysis. Wakayamaken Kankyo Eisei Kenkyu Senta Nenpo (Annual Report of Wakayama Prefectural Research Center of Environment 
and Public Health), 55, 28-34 (2009).

17) Fukuda, M., Umehara, T., Moriya, S. A trial to simplification of food additive analysis in food by dialysis. Osakashiritu Kankyou Kagaku Kenkyujyo, 56, 32-36 (1994).

18）厚生省生活衛生局食品化学課編。“第 10 章甘味料”。第 2 版 食品中の食品添加物分析法. 東京, 日本食品衛生協会, 2000, p. $141-158$.

19) The Pharmaceutical Society of Japan ed. “2.3.8 Kan- miryou". Eiseishikenho Chukai 2010 (Methods of Analysis Health Science 2010). Tokyo, Kanehara Shuppan, 2010, p. 350-370. (ISBN 978-4-307-47039-1)

20) Nishijima, M., Kanmuri, M., Takahashi, N., Kamimura, H., Nakazato, M., Watari, Y., Kimura, Y. Studies on analysis of L-aspartyl-L-phenylalanine methyl ester in foods. Shokuhin Eiseigaku Zasshi (Food Hyg. Sef. Sci.), 17, 78-84 (1976). 